\title{
CORRECTIONS
}

\section{Publisher Correction: Microbial ageing and longevity}

\section{Roy Z. Moger-Reischer(D) and Jay T. Lennon (D)}

Nature Reviews Microbiology (2019) https://doi.org/10.1038/s41579-019-0253-y Published online 18 September 2010

The middle initial of the first author was left out and has now been added, so that the full name, Roy Z. Moger-Reischer, appears in the pdf and online. We apologize to the authors and readers for any confusion caused.

https://doi.org/10.1038/s41579-019-0279-1 I Published online 26 September 2019 